\title{
Effect of Chia Seed Mucilage on the Rhizosphere Hydraulic Characteristics
}

\author{
Faisal Hayat ${ }^{1, *}$, Mohanned Abdalla ${ }^{1}$ and Muhammad Usman Munir ${ }^{2}$ (i) \\ 1 Bayreuth Center of Ecology and Environmental Research (BayCEER), University of Bayreuth, \\ 95447 Bayreuth, Germany; Mohanned.Abdalla-Ali-Abdalla@uni-bayreuth.de \\ 2 Department of Hydrology, University of Bayreuth, 95447 Bayreuth, Germany; \\ Muhammad.Munir@uni-bayreuth.de \\ * Correspondence: Faisal.Hayat@uni-bayreuth.de
}

check for updates

Citation: Hayat, F.; Abdalla, M.; Munir, M.U. Effect of Chia Seed Mucilage on the Rhizosphere

Hydraulic Characteristics.

Sustainability 2021, 13, 3303.

https://doi.org/10.3390/su13063303

Received: 27 January 2021

Accepted: 12 March 2021

Published: 17 March 2021

Publisher's Note: MDPI stays neutral with regard to jurisdictional claims in published maps and institutional affiliations.

Copyright: (c) 2021 by the authors. Licensee MDPI, Basel, Switzerland. This article is an open access article distributed under the terms and conditions of the Creative Commons Attribution (CC BY) license (https:/ / creativecommons.org/licenses/by/ $4.0 /)$.

\begin{abstract}
The rhizosphere is one of the major components in the soil-plant-atmosphere continuum which controls the flow of water from the soil into roots. Plant roots release mucilage in the rhizosphere which is capable of altering the physio-chemical properties of this region. Here, we showed how mucilage impacted on rhizosphere hydraulic properties, using simple experiments. An artificial rhizosphere, treated or not with mucilage, was placed in a soil sample and suction was applied to mimic the negative pressure in plant xylem. The measured water contents and matric potential were coupled with numerical models to estimate the water retention curve and hydraulic conductivity. A slower loss of water was observed in the treated scenario which resulted in an increase in water retention. Moreover, a slightly lower hydraulic conductivity was initially observed in the treated scenario $\left(8.44 \times 10^{-4} \mathrm{~cm} \mathrm{~s}^{-1}\right)$ compared to the controlled one in saturated soil. Over soil drying, a relatively higher unsaturated hydraulic conductivity was observed. In summary, we demonstrated that mucilage altered the rhizosphere hydraulic properties and enhanced the unsaturated hydraulic conductivity. These findings improve our understanding of how plants capture more water, and postulate that mucilage secretion could be an optimal trait for plant survival during soil drying.
\end{abstract}

Keywords: rhizosphere; chia seed; mucilage; soil drying; water retention; hydraulic conductivity

\section{Introduction}

Water scarcity is the major constrain limiting plant growth. Additionally, due to sparse and irregular precipitation, the risk of drought spells could increase around the globe. Therefore, understanding the strategies that plants adopt to cope with the drought spells is of high interest. To overcome the drought stresses, apart from others, plants close stomata resulting in a reduction in transpiration [1], grow more roots deep enough to extract water from the subsoil [2-4], change the location of water uptake to the deep wetter regions [5,6], and redistribute water in the shallow dry regions [7-10]. Besides the above-mentioned strategies, plants may change the dynamic properties of the surrounding soil-the rhizosphere, to extract water and nutrients during soil drying.

The rhizosphere is the narrow region in the vicinity of the roots that hosts a tremendous biodiversity and offers numerous challenges and opportunities to plants [11]. The water flow in the soil-plant continuum flows across the rhizosphere. The rhizosphere development, maturity, and senescence are related to the changes in the subtending region of the roots. There are strong evidences that the rhizosphere differs in physio-chemical properties compared to the surrounding bulk soil [12,13]. Additionally, a higher water content in the rhizosphere compared to the surrounding bulk soil is observed which is due to the mucilage secreted by the roots [14,15], and the physio-chemical properties of mucilage are plant specific $[16,17]$. The higher water content in the rhizosphere could also be due to the soil compaction around the roots [18] and hygroscopic characteristics of mucilage. This narrow region, i.e., the rhizosphere, could strongly impact the flow of 
water from soil to root. Furthermore, it is suggested that the hydraulic characteristics of the rhizosphere could play a key role in extraction of water resources [19].

Recent studies revealed an intimately tied link between belowground conductivity and stomatal closure under water deficit [20-25]. For instance, Carminati and Javaux investigated, by means of meta-analysis and simulations, the hydraulic limitations of water flow in the soil-plant-atmosphere continuum. The authors also demonstrated that soil, rather than xylem hydraulic conductance, triggers stomatal closure. The decrease in soil-plant hydraulic conductance drove transpiration reduction in maize (Zea mays L.) in response to soil drying [21] and it was further suggested that the loss in soil-root hydraulic conductance triggered stomatal closure in tomato (Solanum lycopersicon L.) under drought conditions [23]. Therefore, there is an urgent need to shed light on the mechanisms by which plants alter rhizosphere hydraulic characteristics during soil drying, and mucilage is a potential candidate in this regard.

Mucilage is a polymeric gel released by the roots and is mainly composed of polysaccharides that confer to mucilage their hydrogel nature [26]; for instance, they form an interconnected structure [27] and increase its viscosity $[16,17,28]$. This acts like a porous matrix enabling the mucilage to absorb and hold a large amount of water $[17,28-31]$ and this helps the protection of roots during the drought incidences [31]. Furthermore, the exuded mucilage also comprises of some fractions of lipids [32] which cause the reduction of surface tension at the gas-liquid interface [32-34]. Additionally, the presence of lipids could explain the hydrophobic nature of the rhizosphere at lower water contents $[35,36]$. The general effects of root mucilage and seed mucilage on their intrinsic properties are listed in Table 1.

Table 1. Intrinsic properties of root and seed mucilage.

\begin{tabular}{ccc}
\hline Intrinsic Properties & Root Mucilage & Seed Mucilage \\
\hline Viscosity & $\begin{array}{c}\text { Viscosity increases with } \\
\text { increase in concentration of } \\
\text { root exudate }\end{array}$ & $\begin{array}{c}\text { Viscosity increases with } \\
\text { increase in concentration of } \\
\text { seed exudate }\end{array}$ \\
\hline Water Adsorption & Up to 5.25 g water/g exudate & Up to 44 g water/g mucilage \\
\hline Surface tension & $\begin{array}{c}\text { Surface tension decreases with } \\
\text { increase in concentration of } \\
\text { root exudate }\end{array}$ & $\begin{array}{c}\text { Surface tension decreases with } \\
\text { increase in concentration of } \\
\text { seed exudate }\end{array}$ \\
\hline
\end{tabular}

Despite the variations in intrinsic properties of mucilage, its effects on the rhizosphere hydraulics are still unclear. In this study, we aimed to investigate, using a simple experimental and numerical approach, the effect of mucilage on the hydraulic properties of the rhizosphere. Here, we used seed mucilage, as a substitute to root mucilage, extracted from chia seeds (Salvia hispanica L.). Biochemically, chia seed mucilage is composed of $64 \%$ sugars, $13.3 \%$ organic acids, $2 \%$ fatty acids, and $1.1 \%$ amino acids [16]. Chia seed mucilage is identical to that of maize in chemical composition, and both are composed of glucose, xylose, and with $25 \%$ content of uronic acids [37]. Moreover, chia seeds mucilage has the same physical behavior as that of lupine (Lupinus albus L.) and maize, for instance, swelling, hydrophobicity, and forms a hydrogel structure that is capable of holding a large amount of water [38].

Here, artificial root, coated with the soil mixed with the known concentration mucilage, here termed as rhizosphere, was placed in the soil samples with higher water content (WC $\approx 0.35 \mathrm{~cm}^{3} \mathrm{~cm}^{-3}$ ) and suction was applied to extract water from the soil via an artificial root. We measured the change over time in water content and matric potential of the soil sample. The measured data was coupled with numerical models to estimate the water retention curve and hydraulic conductivity. The novelty of this study was to test, using a simple method, the hypothesis that the presence of mucilage alters the hydraulic characteristics of the rhizosphere in the dry soil. In a complementary simple experiment, 
we estimated to what extent the rhizosphere unsaturated hydraulic conductivity increases in the presence of mucilage in relatively dry soil.

\section{Materials and Methods}

\subsection{Mucilage Extraction}

Mucilage from chia seeds was used as an alternative to that of plant mucilage. Mucilage was extracted from chia seeds by adding $20 \mathrm{~g}$ of seeds into $200 \mathrm{~mL}$ of distilled water in a beaker and the mixture was stirred for $10 \mathrm{~min}$ with a magnetic stirrer. Then it was kept for $2 \mathrm{~h}$ at room temperature to hydrate the seeds. The produced mucilage was extracted from the mixture through a sieve with mesh size of $0.5 \mathrm{~mm}$ by applying a suction of 1 bar. To remove the remaining seeds from the extracted mucilage, it was passed again through a sieve with mesh size of $0.2 \mathrm{~mm}$.

\subsection{Artificial Rhizosphere Preparation}

The artificial rhizosphere was prepared by using fine sand with particle size $<500 \mu \mathrm{m}$. The artificial rhizosphere was made up in the laboratory as a substitute for actual rhizosphere. For making the artificial rhizosphere, a porous suction tube (Rhizons SMS (19.21.05), Rhizosphere Research Products B.V. The Netherlands) with a radius of $0.1 \mathrm{~cm}$ and a length of $5 \mathrm{~cm}$ was used. This suction tube, acting as the root, was coated carefully with the mixture of sand and mucilage with a concentration of $0.1 \%$. To achieve the required concentration, $0.62 \mathrm{~g}$ of wet mucilage and $3.42 \mathrm{~g}$ of dry soil was required. The prepared rhizosphere was let to dry for $72 \mathrm{~h}$ at room temperature. When the rhizosphere became stable, it was further used for experiments.

\subsection{Soil Sample Preparation}

The soil (same as used in the previous section) was poured into plastic bottles $(6 \times 6 \mathrm{~cm})$ in such a way that the bulk density of soil was $1.45 \mathrm{~g} / \mathrm{cm}^{3}$. Note that prior to adding the soil, firstly the artificial rhizosphere was placed in the bottle then the soil was added. For each sample, $120 \mathrm{~g}$ of soil was used. Then, each sample was put on the balance and $29 \mathrm{~g}$ of water was added slowly, with the help of a syringe, from the bottom of the soil sample to remove all air from the sample which resulted in the water content of $35 \mathrm{~cm}^{3} \mathrm{~cm}^{-3}$. The initial conditions were kept constant for all replications. We tested three replications without rhizosphere (hereinafter referred to as "controlled") and three with rhizosphere (hereinafter referred to as "treated"). Afterwards, the controlled and treated samples were allowed to equilibrate for $30 \mathrm{~min}$ and $48 \mathrm{~h}$, respectively. A layer of fine gravel (2-3.5 $\mathrm{mm})$ was added on the soil surface to minimize evaporation.

\subsection{Experimental Setup}

The soil sample was kept on an electronic weight balance. The open end of the porous tube (the artificial root) was connected with a vacuum pump (Kaeser-Kompressor Premium Compact (160/4W), Coburg, Germany) via a beaker. A micro tensiometer (T5, UMS AG, Munich, Germany) was installed at a distance of $2.5 \mathrm{~cm}$ away from the artificial rhizosphere. The tensiometer was connected to the data logger to record data. The suction tube and the tensiometer's wire were fixed firmly so that these may not disturb the weight balance readings. Finally, the weight balance and data logger were connected with a computer to record data. The schematic diagram of the experimental setup is shown in Figure 1.

A suction ranging between 0.38 to 0.41 bar was applied with the vacuum pump to extract water from the sample. As suction reached 0.38 bar, the vacuum pump started automatically, and suction was increased to 0.41 bar. The extracted water from the sample was collected in a beaker. When everything was connected and installed, the sample was again allowed to reach equilibrium conditions. The change in weight and matric potential were recorded simultaneously with intervals of $10 \mathrm{~s}$ until the change in weight and matric potential readings became approx. zero. For the controlled experiments, the data was recorded for $1 \mathrm{~h}$. While in the case of the treated experiments, the data was recorded with 
intervals of $10 \mathrm{~s}$ for the first $10 \mathrm{~min}$ then the interval was changed to $10 \mathrm{~min}$, and measuring continued for $48-72 \mathrm{~h}$ until the change in weight and matric potential became zero.

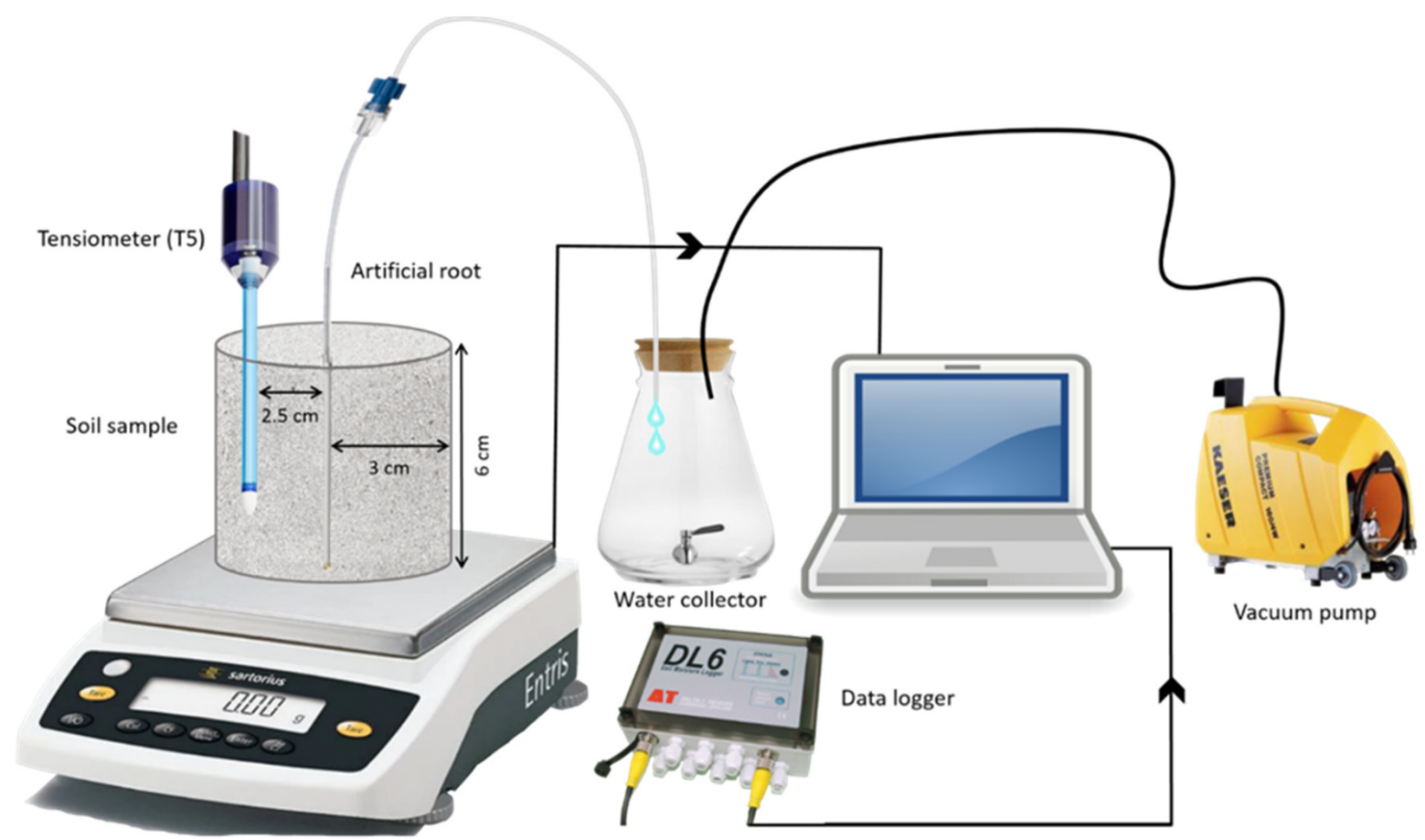

Figure 1. The schematic of the experimental setup.

From the measurements, the volumetric water content, $\theta\left(\mathrm{cm}^{3} \mathrm{~cm}^{-3}\right)$, was calculated by:

$$
\theta=\frac{\Delta W}{W_{\text {soil }}} \times \rho_{\text {soil }}
$$

where $\Delta W$ is the change in weight $\left(\mathrm{cm}^{3}\right), W_{\text {soil }}$ is the weight of soil $(\mathrm{g})$, and $\rho_{\text {soil }}$ is the soil bulk density $\left(\mathrm{g} \mathrm{cm}^{-3}\right)$.

\subsection{Numerical Modelling}

The measured data were used to calculate the flux $\left(\mathrm{cm} \mathrm{s}^{-1}\right)$ and were inversely simulated to calculate the water retention curve and unsaturated hydraulic conductivity $\left(\mathrm{cm} \mathrm{s}^{-1}\right)$ of the soil. The soil parameters were fitted inversely by solving the Richard's equation. The Richard's equation can be written by considering either moisture content, $\theta\left(\mathrm{cm}^{3} \mathrm{~cm}^{-3}\right)$, or pressure head, $h(\mathrm{~cm})$, as dependent variables. An implicit scheme was used for the simulation of water flow. In this implicit scheme, a system of equations was solved iteratively in radial coordinates over time. The schematic of the simulation of the model, for both the control and treated cases, is presented in Figure 2. The Richard's equation in radial coordinates can be formulated as:

$$
\frac{\partial \theta}{\partial t}=C(h) \frac{\partial h}{\partial t}=-\frac{q}{r}-\frac{\partial q}{\partial r}-S
$$

or

$$
\begin{gathered}
C(h) \frac{\partial h}{\partial t}=-\frac{\partial(r q)}{r \partial r}-S \\
C(h) \frac{\partial h}{\partial t}=\frac{1}{r} \frac{\partial}{\partial r}\left[r K(h, \theta) \frac{\partial H}{\partial r}\right]
\end{gathered}
$$

where $C(h)=d \theta / d h$ is the water capacity $\left(\mathrm{cm}^{-1}\right)$ as a function of pressure head, $t$ is time (s), $r$ is radial distance from the center of the root $(\mathrm{cm}), q$ is water flux $\left(\mathrm{cm} \mathrm{s}^{-1}\right), H$ is the 
hydraulic head $(\mathrm{cm}), K$ is the unsaturated hydraulic conductivity $\left(\mathrm{cm} \mathrm{s}^{-1}\right)$, and $S$ is source or sink. To solve the Richard's equation in radial coordinates, we assumed that: (i) there is no gravitational component $(H=h)$, (ii) water flows radially towards the root, (iii) there is no source or sink, water flows out just through the $\operatorname{root}(S=0)$, and (iv) the flux at the innermost compartment, i.e., in the artificial rhizosphere, is equal to the flux entering into the root.

\section{(a)}

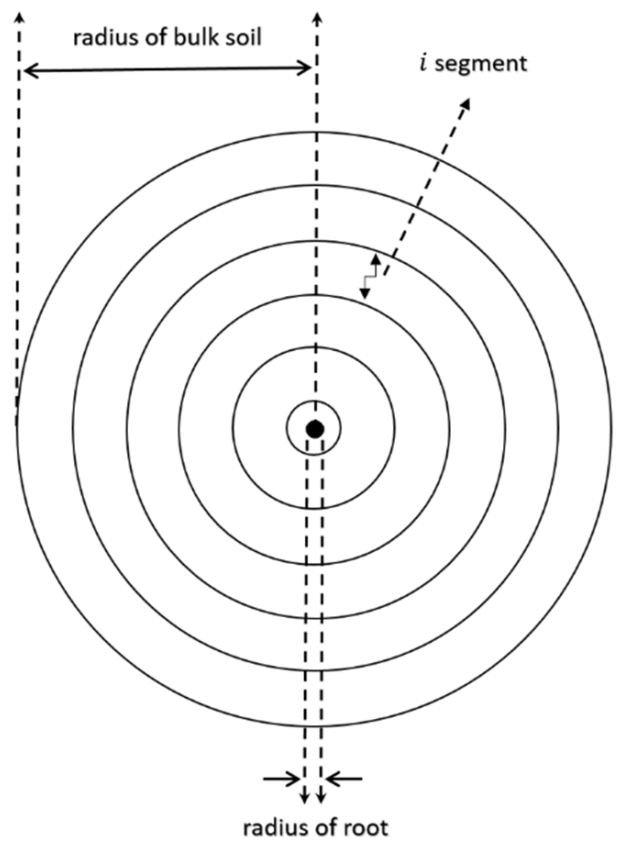

(b)

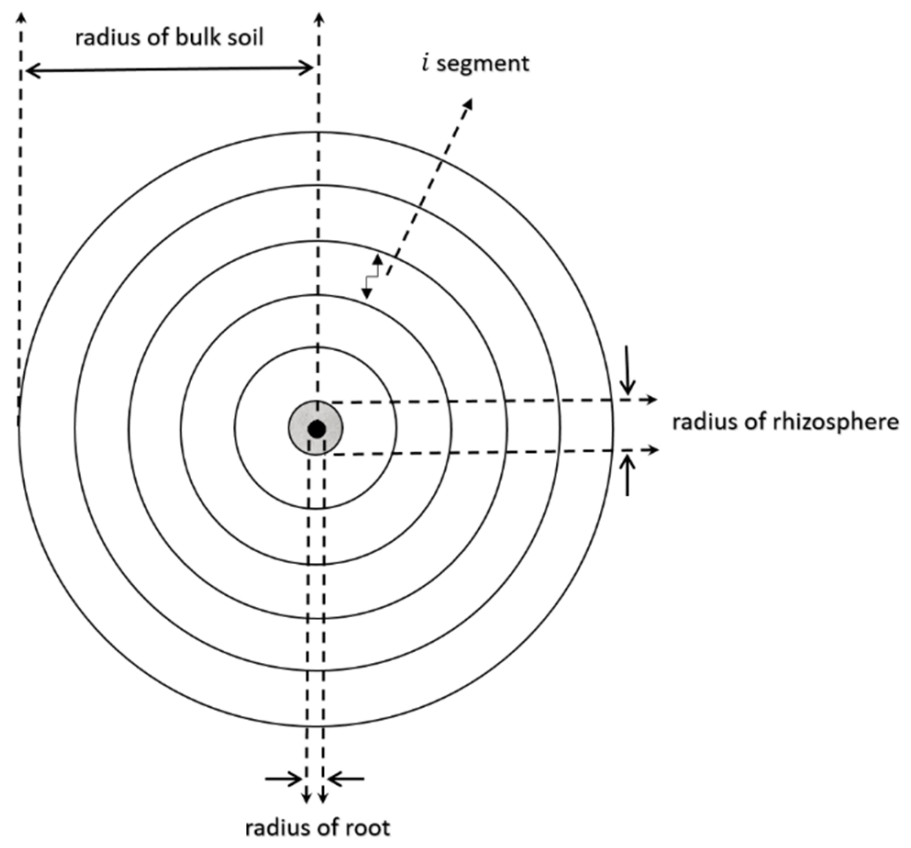

Figure 2. The schematic of the radial model. $(\mathbf{a}, \mathbf{b})$ represent the control and treated cases.

According to the assumptions described above, Equation (4) can be written as:

$$
C(h) \frac{\partial h}{\partial t}=\frac{1}{r} \frac{\partial}{\partial r}\left[r K(h, \theta) \frac{\partial h}{\partial r}\right]
$$

Equation (5) was discretized explicitly for $K$ and $C$ as follows

$$
\begin{gathered}
\frac{h_{i}^{j+1}-h_{i}^{j}}{\Delta t^{j}}=\frac{r_{i-0.5} K_{i-0.5}^{j} \frac{\Delta h_{i-0.5}^{j+1}}{r_{i}-r_{i-1}}-r_{i+0.5} K_{i+0.5}^{j} \frac{\Delta h_{i+1}^{j+1} r_{i}}{r_{i} C_{i}^{j} \Delta r_{i}}}{C_{i}^{j+1, p-1}\left(h_{i}^{j+1, p}-h_{i}^{j+1, p-1}\right)+\theta_{i}^{j+1, p-1}-\theta_{i}^{j}=} \\
\frac{t^{j+1}-t^{j}}{r_{i} \Delta r_{i}}\left[r_{i-0.5} K_{i-0.5}^{j} \frac{h_{i-1}^{j+1, p}-h_{i}^{j+1, p}}{r_{i}-r_{i-1}}-r_{i+0.5} K_{i+0.5}^{j} \frac{h_{i}^{j+1, p}-h_{i+1}^{j+1, p}}{r_{i+1}-r_{i}}\right]
\end{gathered}
$$

where $i$ is the segment number, $j$ is the time step, and $p$ is the iteration level.

In the model simulation, we used radius of root $=0.125 \mathrm{~cm}$, radius of the rhizosphere $=0.5 \mathrm{~cm}$, and radius of bulk soil $=2.5 \mathrm{~cm}$. The simulations were performed using MATLAB 2019b (MathWorks).

For the model simulation, the initial boundary conditions, listed in Table 2, were used as initial guesses to define the upper and lower boundary conditions of model setup and to obtain the parameters for the best fits for the control and treated samples. 
Table 2. Initial guesses of parameters used for model simulation.

\begin{tabular}{cccccccc}
\hline Parameters & $\boldsymbol{\theta}_{\boldsymbol{s}}(\mathbf{- )}$ & $\boldsymbol{\theta}_{\boldsymbol{r}} \mathbf{( - )}$ & $\boldsymbol{\alpha}\left(\mathbf{c m}^{-\mathbf{1}}\right)$ & $\boldsymbol{n}(\mathbf{- )}$ & $\boldsymbol{K}_{\boldsymbol{s}}\left(\mathbf{c m ~ s}^{-\mathbf{1}}\right)$ & $\lambda(\mathbf{- )}$ & $\boldsymbol{K}_{\text {root }}\left(\mathbf{c m ~ s}^{-\mathbf{1})}\right.$ \\
\hline Lower Limit & 0.34 & 0.017 & 0.001 & 3 & $0.07 \times 10^{-4}$ & -6 & $0.1 \times 10^{-6}$ \\
Upper Limit & 0.47 & 0.06 & 0.06 & 10 & 0.01 & 6 & $10 \times 10^{-6}$ \\
\hline
\end{tabular}

By using the best fit parameters obtained through simulation results, the soil water content as a function of matric potential was calculated using the Van Genuchten equation (Equation (8)) for each scenario. Afterwards, the unsaturated hydraulic conductivity was calculated using the Mualem equation (Equation (9)).

$$
\begin{gathered}
\theta(h)=\theta_{r}+\frac{\theta_{s}-\theta_{r}}{\left[1+|\alpha h|^{n}\right]^{m}} \\
K=K_{s} S^{\lambda}\left[1-\left(1-S^{\frac{1}{n}}\right)^{m}\right]^{2}
\end{gathered}
$$

where $\theta, \theta_{s}, \theta_{r}$, and $S=\left(\theta-\theta_{r}\right) /\left(\theta_{s}-\theta_{r}\right)$ are water content, saturated water content, residual water content (-) and saturation (-), respectively; $K_{s}$ and $K$ are the saturated and unsaturated hydraulic conductivity $\left(\mathrm{cm} \mathrm{s}^{-1}\right)$; $\mathrm{h}$ is the matric potential head $(\mathrm{cm})$ and $\alpha, m$, $n \& \lambda$ are the empirical parameters.

\section{Results}

The decrease in soil water contents for each replication, for both the controlled and treated samples, along with model fits over time are plotted in Figure 3. The soil water content for each replication was calculated using Equation (1). It can be noticed that as the suction was applied, the water extraction or drop in soil water contents was faster in the controlled scenario as compared to the treated scenario. In contrast, in the treated scenario, due to the presence of the rhizosphere, the decrease in water content over time was rather slower. It is worth noting that almost all added water has been extracted from each scenario. Each best fit was obtained through model simulations for all of the replications in both scenarios. The fitted parameters for Van Genuchten's equation obtained through the model simulation for both scenarios are listed in Table 3. By comparing the decrease in water content, it can be seen that the controlled and treated scenarios have different trends in the soil drying over time. This indicates that the presence of mucilage in the rhizosphere increased the viscosity of the fluid, and the soil dried out at a slower rate.

Table 3. The fitted parameters for Van Genuchten's equation for control and treated scenarios.

\begin{tabular}{cccccccc}
\hline Parameters & $\boldsymbol{\theta}_{\boldsymbol{s}}(\mathbf{- )}$ & $\boldsymbol{\theta}_{\boldsymbol{r}} \mathbf{( - )}$ & $\boldsymbol{\alpha}\left(\mathbf{c m}^{-\mathbf{1}}\right)$ & $\boldsymbol{n}(-)$ & $\boldsymbol{K}_{\boldsymbol{s}}\left(\mathbf{c m ~ s}^{-\mathbf{1}}\right)$ & $\lambda(\mathbf{- )}$ & $\boldsymbol{K}_{\text {root }}\left(\mathbf{c m ~ s}^{-\mathbf{1})}\right.$ \\
\hline Controlled & 0.3803 & 0.0170 & 0.0260 & 8.0875 & 0.0060 & 0.0883 & $1 \times 10^{-6}$ \\
Treated & 0.4302 & 0.0300 & 0.0409 & 3.8000 & 0.0009 & -0.1676 & $6.58 \times 10^{-7}$ \\
\hline
\end{tabular}

The drop in soil matric potential over time for both scenarios and their model fits are shown in Figure 4. The trend in drop in matric potential showed similar behavior as was observed for the decrease in water content in both scenarios. In the controlled experiments, the water extraction was faster which resulted in a decline in water potential within a few minutes and then it became constant. The model simulations showed an excellent match of the observed data in the controlled and treated experiments. In the treated scenario, the best fit was obtained by optimizing seven parameters and was following an object function, and the best solution was obtained when the objective function was minimum. These observations reflected that mucilage is affecting and altering the soil behavior. To understand this behavior, the data were further simulated to observe the effect of mucilage on soil characteristics. 


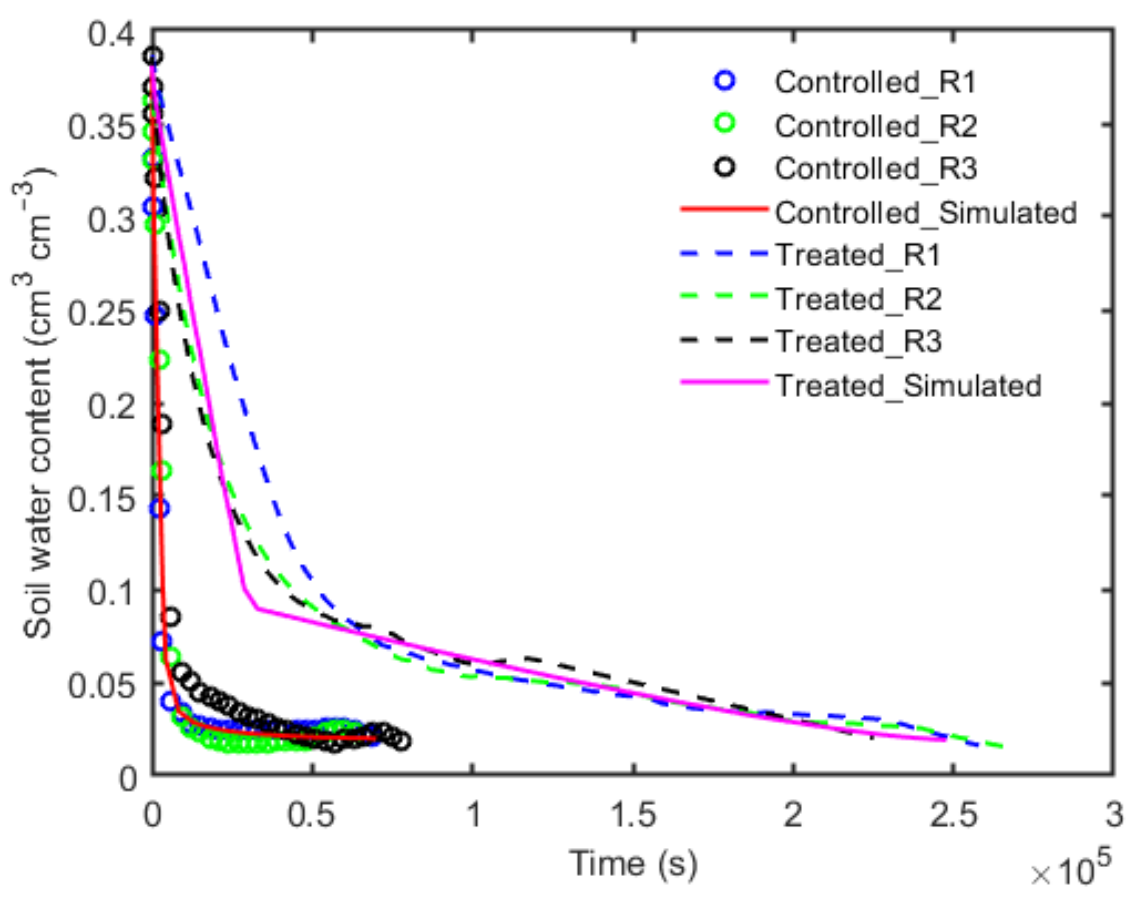

Figure 3. The decrease in soil water content over time. Open symbols indicate the measured data for controlled replications. Dashed lines indicate the measured data for treated replications. Solid lines indicate model fits.

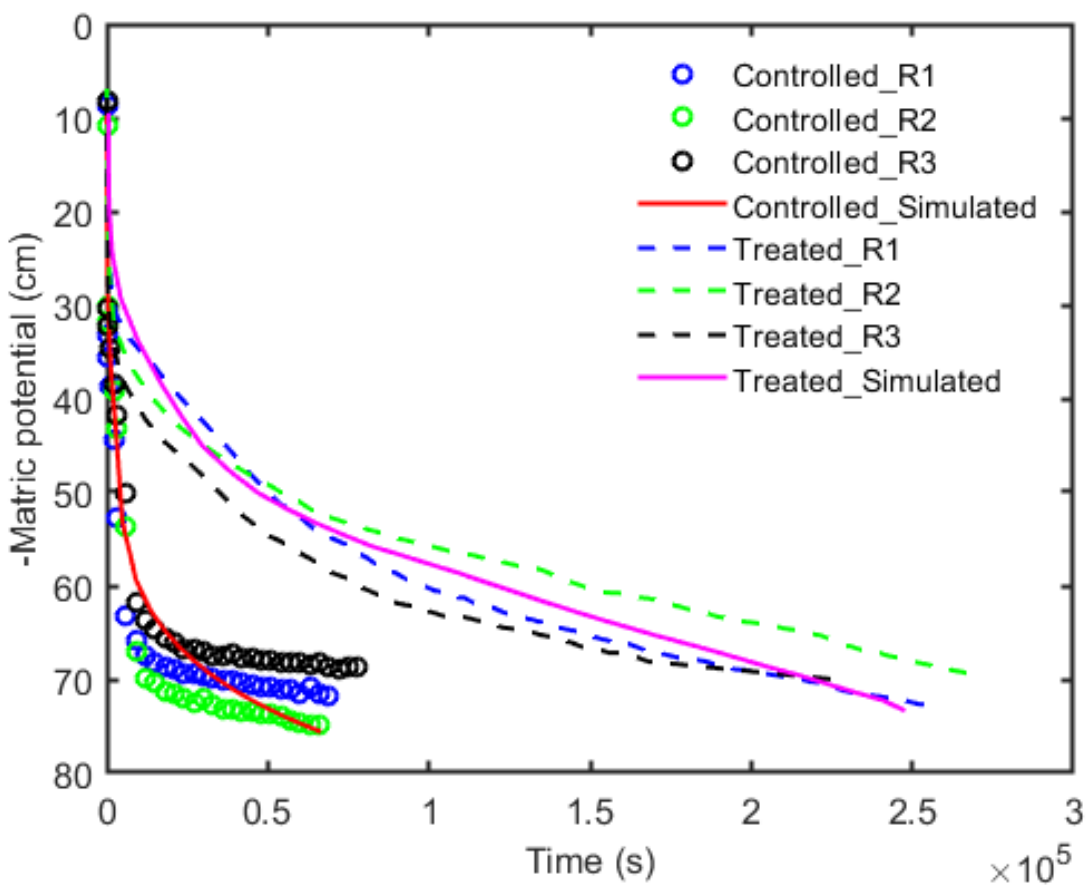

Figure 4. The decrease in soil matric potential over time. Open symbols indicate the measured data for controlled replications. Dashed lines indicate the measured data for treated replications. Solid lines indicate model fits.

The model simulations of variation in soil water content with respect to distance from the root till the location of tensiometer at final time for both scenarios are shown in Figure 5. Firstly, it was observed that the water content in the rhizosphere was higher as compared to the surrounding soil. Secondly, it can be seen that the water content increased over distance from the root, and an abrupt reduction in water content was observed near the 
root in both scenarios. In the controlled scenario, a larger amount of water remained in the soil as compared to the treated sample. A higher water content in the rhizosphere compared to the surrounding bulk soil was also observed.

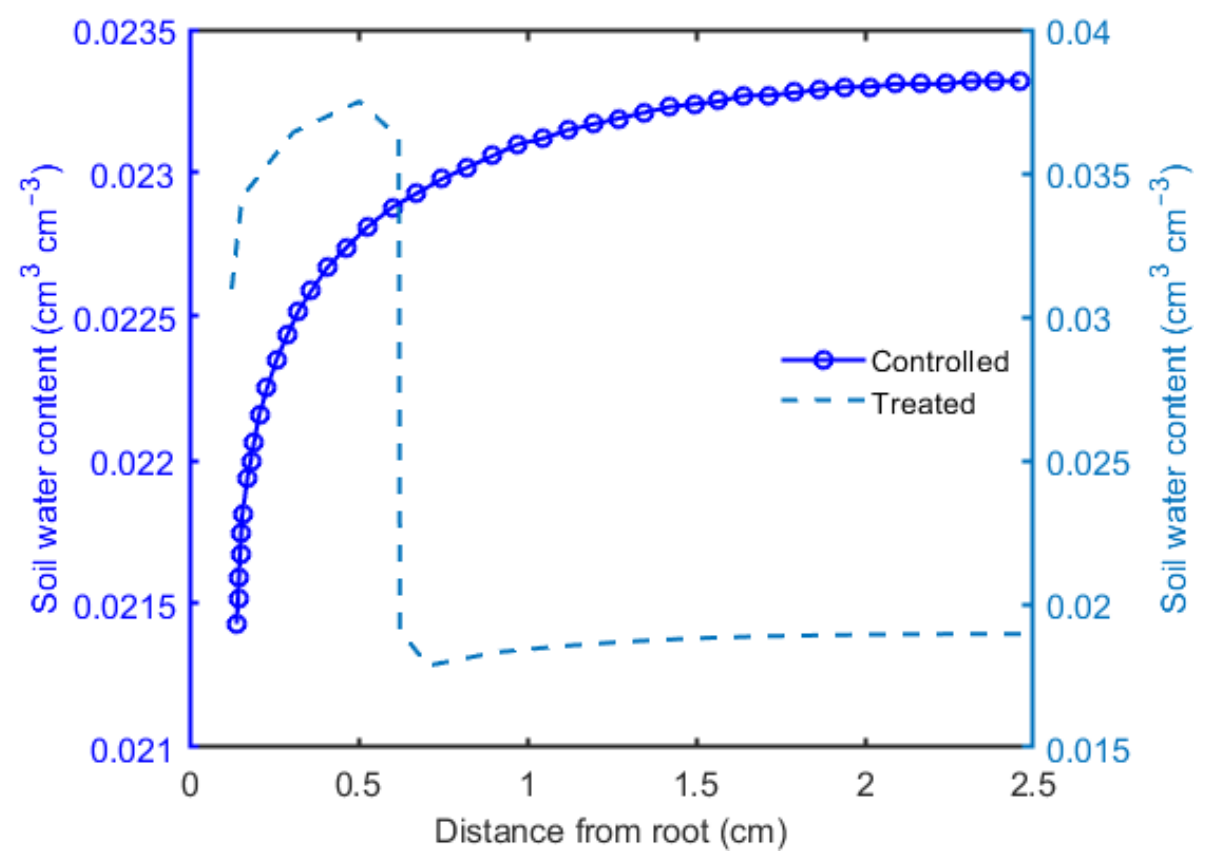

Figure 5. Variation of soil water content over distance from the root for controlled and treated scenarios.

The water retention curves obtained through model simulations for the control and treated scenarios are shown in Figure 6. It can be seen that with an increase in matric potential, the treated scenario started to drain water (at matric potential $\approx 100 \mathrm{~cm}$ ) before the controlled one. However, as matric potential reached approx. $120 \mathrm{~cm}$, the controlled scenario started to dry and was drained of all water at matric potential of approx. $160 \mathrm{~cm}$. This loss in water in the soils is associated with the air entry value-i.e., the minimum matric potential needed to drain the largest pore in the soil. Figure 6 clearly showed that the air entry value of the treated scenario was lower than the controlled. Although the air entry value of the treated scenario is less, it started to drain water slowly as compared to the controlled one. Moreover, it was observed that the treated scenario had a relatively higher water holding capacity.

Another fundamental hydraulic characteristic of soil which was simulated by the model is the soil hydraulic conductivity. The effect of mucilage on the soil unsaturated hydraulic conductivity is shown in Figure 7. Initially, the saturated hydraulic conductivity of the controlled scenario was higher compared to the treated scenario. With an increase in matric potential the unsaturated hydraulic conductivity remained constant but as water started to flow out from the system, the unsaturated hydraulic conductivity decreased exponentially. In the case of the treated scenario, with continuous soil drying, the unsaturated hydraulic conductivity decreased more gradually than the controlled scenario but was higher as compared to the controlled scenario. This indicates that mucilage not only increased the water holding capacity but also impacted on the unsaturated hydraulic conductivity during the soil drying. 


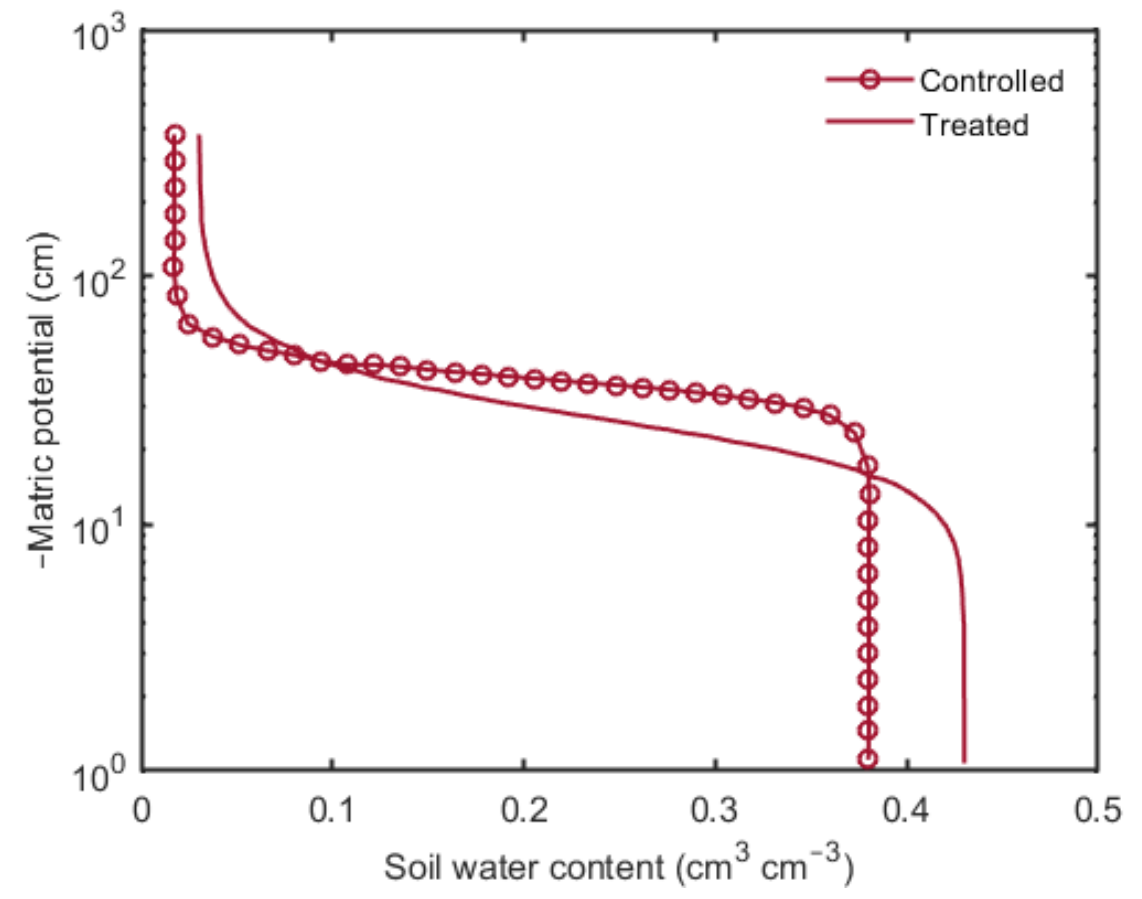

Figure 6. The simulated water retention curves of the controlled and treated scenarios.

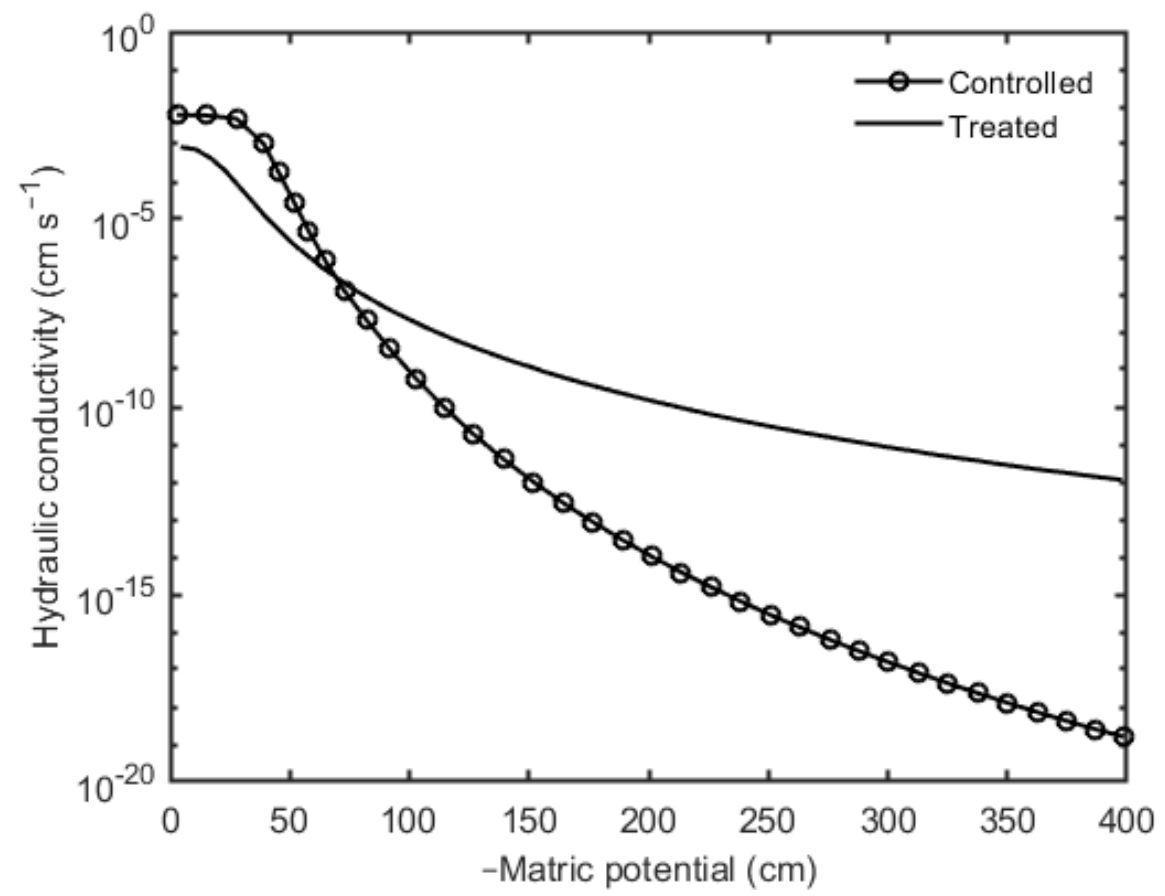

Figure 7. The simulated soil hydraulic conductivity of controlled and treated scenarios.

\section{Discussion and Conclusions}

In this simple experimental and numerical study, we showed the effect of mucilage on the rhizosphere hydraulic characteristics. It was observed that the presence of mucilage increased the unsaturated hydraulic conductivity of the rhizosphere in relatively dry soil which could favor root water uptake. This increase in the rhizosphere unsaturated hydraulic conductivity resulted from the hygroscopic nature of mucilage. Specifically, we observed that: (i) mucilage increased the water holding capacity of the soil (Figures 3 and 6); and (ii) during soil drying, mucilage increased the unsaturated hydraulic conductivity of 
the treated scenario as compared to the controlled one (Figure 7). These results substantiate the hypothesis, proposed by [15], that mucilage increases the water content of the rhizosphere and the findings that it loses all of its water at high matric potentials [31].

Our simple experiments were performed using an artificial root, to avert the intricacy of changeable root conductivity $[39,40]$, which was coated with a known concentration of seed mucilage, here referred to as artificial rhizosphere; and the data were further numerically analyzed to obtain the water retention curve and unsaturated hydraulic conductivity. The decrease in water content over time (Figure 3) clearly showed that mucilage increased the water holding capacity of soil and both scenarios, i.e., the controlled and treated, have slightly different trends during the soil drying. The reason for this trend is the slow drainage of water in the treated scenario which could be well explained by the intrinsic properties of mucilage, like viscous nature and entanglement with the soil particles [41,42]. This result could be further supported by Figure 5 where a higher water content was observed in the rhizosphere in the treated scenario, agreeing with the former evidences that mucilage holds a larger amount of water $[15,31,43,44]$. Figure 5 also indicated that due to the applied suction, the pore spaces near the root became empty and air entered into these spaces resulting in discontinuity in water flow in the controlled scenario, and a larger amount of water remained in the surrounding bulk soil. On the contrary, despite the slower drainage, in the treated scenario almost all of the water was extracted, which is due to the hydraulic continuity between the soil particles and (artificial) roots [41,44-46].

Due to the presence of mucilage, an increase in water retention was observed in the soil amended with mucilage (Figure 6), and a slightly higher residual water content, compared to the controlled scenario, was observed. A higher water retention was observed in the treated scenario at any matric potential. Additionally, the treated soil started to drain water earlier and kept draining until the matric potential reached $200 \mathrm{~cm}$. On the contrary, the controlled soil started to drain later than the treated soil sample, and it lost all of its water by increasing a few centimeters of matric potential. This gradual increase in water retention and higher residual water content could be, possibly, explained by the conceptual model proposed and addressed by [47] that mucilage, depending on its spatial distribution, formed two-dimensional structures on the soil pores which are associated with alteration of macroscopic water dynamics. This increase in water retention, showing good agreement with the previous findings $[41,42,48]$, is due to the inherent affinity of mucilage to absorb water and could maintain the connectivity between the soil and rhizosphere-root interface.

Additionally, the hydraulic conductivity as a function of matric potential (Figure 7) revealed that initially, at saturation, the (saturated) hydraulic conductivity of the treated scenario $\left(8.44 \times 10^{-4} \mathrm{~cm} \mathrm{~s}^{-1}\right)$ was lower compared to the controlled scenario $\left(6.06 \times 10^{-3}\right.$ $\mathrm{cm} \mathrm{s}^{-1}$ ) but its drop with the soil drying was less pronounced. At matric potential of approximately $70 \mathrm{~cm}$, the hydraulic conductivity lines of both scenarios crossed, and afterward, the unsaturated hydraulic conductivity of the treated sample was higher compared to the controlled one at any matric potential. Similarly, this finding was further supported by the previous studies that a lower water flow is expected at saturated soil due to the pore clogging by the viscous nature of mucilage [48,49], and during drying, the drop in unsaturated hydraulic conductivity of the rhizosphere is prevented by maintaining the hydraulic continuity at the soil-root interface or between soil and seeds $[44,50,51]$.

Note that in this simple experimental and numerical study, the promising results were obtained by using the artificial root, seed mucilage, and a simple model. These preferences were functional to conduct competently controlled experiments. Furthermore, it was assumed that the soil amended with mucilage is a persuasive cognate of the rhizosphere and this assumption is to some extent legitimized by the previous observations that the soil amended with mucilage behaves as the rhizosphere [33,36,37,49]. However, we are absolutely acquainted that rhizosphere characteristics differ in plant species, root exudate (for instance, chemical composition), root age, soil type, pore size, and water distribution. In this perception, this study should not be depicted as an endeavor to include them 
in models for the parameterization of hydraulic characteristics of the rhizosphere. It is more appropriate to assert that these simple experiments coupled with simple models are capable to observe the change in rhizosphere hydraulic properties.

In conclusion, we have successfully, using simple experimental and modeling approaches, showed that mucilage plays a key role in alerting the hydraulic properties of the rhizosphere. The results affirmed that mucilage increased water retention and water holding capacity of the rhizosphere and consequently enhanced the unsaturated hydraulic conductivity during soil drying. These dynamic alterations of the rhizosphere hydraulic properties potentially could favor root water uptake, to more effectively use soil resources and increase plants' survival in the drying soils. Further studies in more realistic ways would be beneficial to explore the impact of mucilage on water and nutrients uptake and how it varies among plant species, age, and soil types.

Author Contributions: The three authors (F.H., M.A., and M.U.M.) co-design the research. F.H. carried out the experiments and drafted the manuscript with contributions from M.A. and M.U.M. All authors have read and agreed to the published version of the manuscript.

Funding: This publication was funded by the German Research Foundation (DFG) and the University of Bayreuth in the funding program, Open Access Publishing.

Informed Consent Statement: Not applicable.

Data Availability Statement: Not applicable.

Conflicts of Interest: The authors declare no conflict of interest.

\section{References}

1. Martin-StPaul, N.; Delzon, S.; Cochard, H. Plant resistance to drought depends on timely stomatal closure. Ecol. Lett. 2017, 20, 1437-1447. [CrossRef]

2. Lynch, J.P. Steep, cheap and deep: An ideotype to optimize water and $\mathrm{N}$ acquisition by maize root systems. Ann. Bot. 2013, 112, 347-357. [CrossRef] [PubMed]

3. Sharp, R.E.; Davies, W.J. Root growth and water uptake by maize plants in drying soil. J. Exp. Bot. 1985, 36, 1441-1456. [CrossRef]

4. Zegada-Lizarazu, W.; Iijima, M. Hydrogen stable isotope analysis of water acquisition ability of deep roots and hydraulic lift in sixteen food crop species. Plant Prod. Sci. 2004, 7, 427-434. [CrossRef]

5. Doussan, C.; Pierret, A.; Garrigues, E.; Pagès, L. Water uptake by plant roots: II-Modelling of water transfer in the soil root-system with explicit account of flow within the root system-Comparison with experiments. Plant Soil 2006, 283, 99-117. [CrossRef]

6. Hayat, F.; Ahmed, M.A.; Zarebanadkouki, M.; Cai, G.; Carminati, A. Measurements and simulation of leaf xylem water potential and root water uptake in heterogeneous soil water contents. Adv. Water Resour. 2018, 124, 96-105. [CrossRef]

7. Caldwell, M.M.; Richards, J.H. Hydraulic lift: Water efflux from upper roots improves effectiveness of water uptake by deep roots. Oecologia 1989, 79, 1-5. [CrossRef]

8. Brooks, J.R.; Meinzer, F.C.; Coulombe, R.; Gregg, J. Hydraulic redistribution of soil water during summer drought in two contrasting Pacific Northwest coniferous forests. Tree Physiol. 2002, 22, 1107-1117. [CrossRef]

9. Smart, D.R.; Carlisle, E.; Goebel, M.; Núñez, B.A. Transverse hydraulic redistribution by a grapevine. Plant Cell Environ. 2005, 28, 157-166. [CrossRef]

10. Hayat, F.; Zarebanadkouki, M.; Ahmed, M.A.; Buecherl, T.; Carminati, A. Quantification of hydraulic redistribution in maize roots using neutron radiography. Vadose Zone J. 2020, 99, 1-10. [CrossRef]

11. Philippot, L.; Raaijmakers, J.M.; Lemanceau, P.; Van Der Putten, W.H. Going back to the roots: The microbial ecology of the rhizosphere. Nat. Rev. Microbiol. 2013, 11, 789-799. [CrossRef]

12. Gregory, P.J. Roots, rhizosphere and soil: The route to a better understanding of soil science? Eur. J. Soil Sci. 2006, 57, 2-12. [CrossRef]

13. Hinsinger, P.; Bengough, A.G.; Vetterlein, D.; Young, I.M. Rhizosphere: Biophysics, biogeochemistry and ecological relevance. Plant Soil 2009, 321, 117-152. [CrossRef]

14. Carminati, A.; Moradi, A.B.; Vetterlein, D.; Vontobel, P.; Lehmann, E.; Weller, U.; Vogel, H.J.; Oswald, S.E. Dynamics of soil water content in the rhizosphere. Plant Soil 2010, 332, 163-176. [CrossRef]

15. Young, I.M. Variation in moisture contents between bulk soil and the rhizosheath of wheat (Triticum aestivum L. cv. Wembley). New Phytol. 1995, 130, 135-139. [CrossRef]

16. Naveed, M.; Brown, L.K.; Raffan, A.C.; George, T.S.; Bengough, A.G.; Roose, T.; Sinclair, I.; Koebernick, N.; Cooper, L.; Hackett, C.A.; et al. Plant exudates may stabilize or weaken soil depending on species, origin and time: Effect of plant exudates on rhizosphere formation. Eur. J. Soil Sci. 2017, 68, 806-816. [CrossRef] 
17. Flemming, H.C.; Wingender, J. Relevance of microbial extracellular polymeric substances (EPSs)—Part I: Structural and ecological aspects. Water Sci. Technol. 2001, 43, 1-8. [CrossRef]

18. Aravena, J.E.; Berli, M.; Ghezzehei, T.A.; Tyler, S.W. Effects of root-induced compaction on rhizosphere hydraulic properties X-ray microtomography imaging and numerical simulations. Environ. Sci. Technol. 2011, 45, 425-431. [CrossRef]

19. Sposito, G. Green Water and Global Food Security. Vadose Zone J. 2013, 12, 2-6. [CrossRef]

20. Carminati, A.; Javaux, M. Soil Rather Than Xylem Vulnerability Controls Stomatal Response to Drought. Trends Plant Sci. 2020, 25, 868-880. [CrossRef]

21. Hayat, F.; Ahmed, M.A.; Zarebanadkouki, M.; Javaux, M.; Cai, G.; Carminati, A. Transpiration Reduction in Maize (Zea mays L) in Response to Soil Drying. Front. Plant Sci. 2020, 10, 1695. [CrossRef]

22. Rodriguez-Dominguez, C.M.; Brodribb, T.J. Declining root water transport drives stomatal closure in olive under moderate water stress. New Phytol. 2020, 225, 126-134. [CrossRef]

23. Abdalla, M.; Carminati, A.; Cai, G.; Javaux, M.; Ahmed, M.A. Stomatal closure of tomato under drought is driven by an increase in soil-root hydraulic resistance. Plant Cell Environ. 2021, 44, 425-431. [CrossRef]

24. Cuneo, I.F.; Knipfer, T.; Brodersen, C.R.; McElrone, A.J. Mechanical failure of fine root cortical cells initiates plant hydraulic decline during drought. Plant Physiol. 2016, 172, 1669-1678. [CrossRef]

25. Carminati, A.; Ahmed, M.A.; Zarebanadkouki, M.; Cai, G.; Lovric, G.; Javaux, M. Stomatal closure prevents the drop in soil water potential around roots. New Phytol. 2020, 226, 1541-1543. [CrossRef] [PubMed]

26. Zha, J.; Roggendorf, H. Sol-gel science, the physics and chemistry of sol-gel processing, Ed. by C. J. Brinker and G. W. Scherer, Academic Press, Boston 1990, xiv, 908 pp., bound?ISBN 0-12-134970-5. Adv. Mater. 1991, 3, 522. [CrossRef]

27. Flemming, H.C.; Wingender, J. The biofilm matrix. Nat. Rev. Microbiol. 2010, 8, 623-633. [CrossRef] [PubMed]

28. Read, D.B.; Gregory, P.J. Surface tension and viscosity of axenic maize and lupin root mucilages. New Phytol. 1997, 137, 623-628. [CrossRef]

29. Read, D.B.; Gregory, P.J.; Bell, A.E. Physical properties of axenic maize root mucilage. Plant Soil 1999, 211, 87-91. [CrossRef]

30. Segura-Campos, M.R.; Ciau-Solís, N.; Rosado-Rubio, G.; Chel-Guerrero, L.; Betancur-Ancona, D. Chemical and functional properties of chia seed (Salvia hispanica L.) gum. Int. J. Food Sci. 2014, 2014, 1-5. [CrossRef]

31. McCully, M.E.; Boyer, J.S. The expansion of maize root-cap mucilage during hydration. 3. Changes in water potential and water content. Physiol. Plant. 1997, 99, 169-177. [CrossRef]

32. Read, D.B.; Bengough, A.G.; Gregory, P.J.; Crawford, J.W.; Robinson, D.; Scrimgeour, C.M.; Young, I.M.; Zhang, K.; Zhang, X. Plant roots release phospholipid surfactants that modify the physical and chemical properties of soil. New Phytol. 2003, 157, 315-326. [CrossRef]

33. Raaijmakers, J.M.; de Bruijn, I.; Nybroe, O.; Ongena, M. Natural functions of lipopeptides from Bacillus and Pseudomonas: More than surfactants and antibiotics. FEMS Microbiol. Rev. 2010, 34, 1037-1062. [CrossRef] [PubMed]

34. Naveed, M.; Brown, L.K.; Raffan, A.C.; George, T.S.; Bengough, A.G.; Roose, T.; Sinclair, I.; Koebernick, N.; Cooper, L.; Hallett, P.D. Rhizosphere-Scale Quantification of Hydraulic and Mechanical Properties of Soil Impacted by Root and Seed Exudates. Vadose Zone J. 2018, 17, 170083. [CrossRef]

35. Moradi, A.B.; Carminati, A.; Vetterlein, D.; Vontobel, P.; Lehmann, E.; Weller, U.; Hopmans, J.W.; Vogel, H.-J.; Oswald, S.E. Three-dimensional visualization and quantification of water content in the rhizosphere. New Phytol. 2011, 192, 653-663. [CrossRef]

36. Carminati, A.; Vetterlein, D. Plasticity of rhizosphere hydraulic properties as a key for efficient utilization of scarce resources. Ann. Bot. 2013, 112, 277-290. [CrossRef] [PubMed]

37. Lin, K.Y.; Daniel, J.R.; Whistler, R.L. Structure of chia seed polysaccharide exudate. Carbohydr. Polym. 1994, 23, 13-18. [CrossRef]

38. Singh, B.; Chauhan, G.S.; Kumar, S.; Chauhan, N. Synthesis, characterization and swelling responses of $\mathrm{pH}$ sensitive psyllium and polyacrylamide based hydrogels for the use in drug delivery (I). Carbohydr. Polym. 2007, 67, 190-200. [CrossRef]

39. Steudle, E. Water uptake by plant roots: An integration of views. Plant Soil 2000, 226, 45-56. [CrossRef]

40. Maurel, C.; Verdoucq, L.; Luu, D.T.; Santoni, V. Plant aquaporins: Membrane channels with multiple integrated functions. Annu. Rev. Plant Biol. 2008, 59, 595-624. [CrossRef]

41. Benard, P.; Zarebanadkouki, M.; Brax, M.; Kaltenbach, R.; Jerjen, I.; Marone, F.; Couradeau, E.; Felde, V.J.M.N.L.; Kaestner, A.; Carminati, A. Microhydrological Niches in Soils: How Mucilage and EPS Alter the Biophysical Properties of the Rhizosphere and Other Biological Hotspots. Vadose Zone J. 2019, 18, 1-10. [CrossRef]

42. Kroener, E.; Holz, M.; Zarebanadkouki, M.; Ahmed, M.; Carminati, A. Effects of Mucilage on Rhizosphere Hydraulic Functions Depend on Soil Particle Size. Vadose Zone J. 2018, 17, 170056. [CrossRef]

43. GUINEL, F.C.; McCULLY, M.E. Some water-related physical properties of maize root-cap mucilage. Plant Cell Environ. 1986, 9 , 657-666. [CrossRef]

44. Ahmed, M.A.; Kroener, E.; Holz, M.; Zarebanadkouki, M.; Carminati, A. Mucilage exudation facilitates root water uptake in dry soils. Funct. Plant Biol. 2014, 41, 1129-1137. [CrossRef] [PubMed]

45. Carminati, A.; Schneider, C.L.; Moradi, A.B.; Zarebanadkouki, M.; Vetterlein, D.; Vogel, H.-J.; Hildebrandt, A.; Weller, U.; Schüler, L.; Oswald, S.E. How the Rhizosphere May Favor Water Availability to Roots. Vadose Zone J. 2011, 10, 988-998. [CrossRef]

46. Dakora, F.D.; Phillips, D.A. Root exudates as mediators of mineral acquisition in low-nutrient environments. Plant Soil 2002, 245, 35-47. [CrossRef] 
47. Benard, P. Microhydrological Niches in Soils: How Mucilage and EPS alter Soil Hydraulic Properties and Water Dynamics. Ph.D. Thesis, University of Bayreuth, Bayreuth, Germany, 2020.

48. Kroener, E.; Zarebanadkouki, M.; Kaestner, A.; Carminati, A. Nonequilibrium water dynamics in the rhizosphere: How mucilage affects water flow in soils. Water Resour. Res. 2014, 50, 6479-6495. [CrossRef]

49. Kroener, E.; Zarebanadkouki, M.; Bittelli, M.; Carminati, A. Simulation of root water uptake under consideration of nonequilibrium dynamics in the rhizosphere. Water Resour. Res. 2016, 52, 5755-5770. [CrossRef]

50. Carminati, A.; Zarebanadkouki, M.; Kroener, E.; Ahmed, M.A.; Holz, M. Biophysical rhizosphere processes affecting root water uptake. Ann. Bot. 2016, 118, 561-571. [CrossRef] [PubMed]

51. Deng, W.; Hallett, P.D.; Jeng, D.S.; Squire, G.R.; Toorop, P.E.; Iannetta, P.P.M. The effect of natural seed coatings of Capsella bursa-pastoris L. Medik. (shepherd's purse) on soil-water retention, stability and hydraulic conductivity. Plant Soil 2015, 387, 167-176. [CrossRef] 